\title{
Greenery in Intermediate Spaces of the Dwellings in the City of Barcelona
}

\author{
Fabiola Meignen*, Anna Martínez, Nuría Martí \\ Department of Architecture, University Ramón Llull, Campus La Salle, Barcelona 08022, Spain
}

Corresponding Author Email: fabiolameignen@gmail.com

https://doi.org/10.18280/ijsdp.150602

Received: 6 January 2020

Accepted: 12 July 2020

\section{Keywords:}

greenery, vegetation, intermediate spaces, Mediterranean climate, Mediterranean architecture

\begin{abstract}
The research intends to develop new forms of naturalization of the city by introducing greenery in the existing buildings of Barcelona. The research is part of a doctoral thesis developed in the University Ramon Llull, Campus La Salle, jointly with the investigation group IAR-IAM (Investigation of Mediterranean Architecture), and La Casa por el Tejado (LCT), a company specialized in industrialized housing projects, incorporating new penthouses on the rooftops of existing buildings with the potential to be vertically expanded. These industrialized penthouses are located in the Eixample District, which is suffering the greatest intensity of urban heat island (UHI) effects and the highest levels of pollution. For this reason, the investigation seeks to innovate technical solutions that incorporate vegetation into the architectural projects of LCT. The urban plot where these buildings are located presents many discontinuities in its morphology due to several changes in urban regulations through the years. This research looks to naturalize the intermediate spaces and surfaces that give continuity to the urban fabric, such as galleries, party walls, rooftops and block courtyards, in order to improve their environmental performance, the biodiversity in their surroundings and, ultimately, increase the quality of life of Barcelona's residents.
\end{abstract}

\section{INTRODUCTION}

The following investigation proposes paths to implement greenery in the intermediate spaces and surfaces of the dwellings in Barcelona as a possible solution to complete and naturalize the urban skyline of the city, improve the quality of the air, mitigate the heat island effect and the quality of life of its citizens.

Nowadays the city of Barcelona is dealing with environmental problems related with high levels of pollution and urban heat islands [1]. The city presents particle matter concentration up to $56 \mathrm{ug} / \mathrm{m}^{3}$, noise levels over $65 \mathrm{Db}$, ozone $\left(\mathrm{O}_{3}\right)$ levels up to $180 \mathrm{ug} 7 \mathrm{~m}^{3}$ and nitrogen dioxide $\left(\mathrm{NO}_{2}\right)$ levels up to $200 \mathrm{ug} 7 \mathrm{~m}^{3}$ [2].

Greenery is able to mitigate these effects by reducing acoustic pollutants, removing atmospheric pollutants from the air such as such as ozone $\left(\mathrm{O}_{3}\right)$, sulfur dioxide $\left(\mathrm{SO}_{2}\right)$, nitrogen dioxide $\left(\mathrm{NO}_{2}\right)$, carbon monoxide $(\mathrm{CO})$ and particle matter, as well as improving the thermal comfort $[3,4]$. In this way, the research relies on the introduction of greenery in a domestic scale to mitigate the negative effects of pollution and improve the quality of life of Barcelona inhabitants.

The investigation is part of an industrial doctorate between the University Ramon Llull with the investigation group IARIAM (Integrated Architectural Research) and the architecture company La Casa por el Tejado ("LCT").

The IAR-IAM is an investigation group focused on the analysis of the Mediterranean architecture, for instance, in the principles of implantation in the territory and the use of the materials and own constructive systems.

LCT is an architecture company, specialized in the development of industrialized housing projects in dense cities.
They execute industrialized flats out of the construction site and place them on the rooftops of existing buildings that have the potential to grow vertically. They also consolidate the common areas of the existing building.

Different penthouses have been analyzed in other to understand the diverse typologies of intermediate spaces and established a methodology of action to implement greenery in each one of them.

At the same time, qualitative interviews were carried on to architects and technicians involved in the design and execution of these projects in order to understand their vision about implementing greenery in intermediate spaces of dwellings.

In this way, it is possible to understand how the introduction of vegetation in dwellings at a domestic scale generates positive impacts in the users' well-being and in the environment, favoring the atmosphere purification by regulating the humidity and temperature.

\section{THE CITY OF BARCELONA}

The investigation takes place in Barcelona, a dense city that is bounded by the Mediterranean Sea, the Collserola mountain range and the Besos and Llobregat rivers. The city has a Mediterranean climate that consists in dry and warm summers, and cold and humid winters. The average annual temperature is $17.6^{\circ} \mathrm{C}$, with a maximum temperature of $28^{\circ} \mathrm{C}$ in summer and a minimum temperature of $2.6^{\circ} \mathrm{C}$ in winter [1].

One of the most characteristic neighborhoods in urban terms is the Eixample District, known because of its successful urban plot, due to its ability to accommodate different uses and its adaptability over time without affecting its morphology. This 
neighborhood was design by Ildefons Cerdà in 1859, he planned a regular extensible plot of octagonal blocks and central open gardens that, over the years, were transformed into patios [5]. The premise of the central garden was ignored until the rehabilitation and improvement Ordinance in 1986 [6].

Each block measures $113 \times 133$ surrounded by streets between 20 meters and 60 meters. The position of the octagonal block vertices coincides with the cardinal points, taking full advantage of the direction of the winds between the sea and the Collserola mountain range to facilitate oxygenation and cleaning of the air (Figure 1).

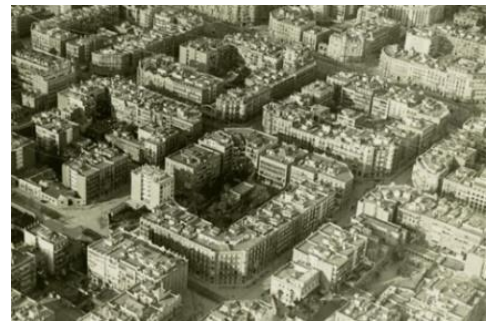

Figure 1. The Eixample plot. Image from Photographic Archive of Barcelona

The initial idea of Cerdá was to establish blocks with two building structures in their perimeter separated from each other generating a central accessible garden. The City Hall did not accept this proposal, instead, it permitted to construct these buildings in all the perimeter with different buildable depth occupying the central patio at the ground floor [7]. Nowadays, most of these interior patios have been recovered by the city.

Ildefons Cerdà from the beginning paid close attention to solve urban problems related to hygiene and the environment, always emphasizing the incorporation of green areas through the public space. His intention could be seen in the position of the blocks and wide streets that favors the ventilation that goes from the mountain to the sea; in his initial block proposal with an open accessible interior green garden; and in their urban configuration with tree-lined streets.

Cerdá chose the specie Platanus $x$ hispanica for a variety of reasons, among which the following can be named: its fast growing rate, its capacity to regulate the humidity, to dampen the urban noise, to tolerate drastic pruning, paving covering and air pollution. In addition, is one of the species with the biggest potential of $\mathrm{CO}_{2}$ absorption. Its fast-growing rate and its large scale make it a suitable tree to be planted in most of the streets in the city [8]. Other species that can be found in the Eixample streets are the Celtis australis, the Ulmus minor and the Ligustrum lucidum.

However, despite these efforts, during the last years the city is facing several environmental problems originated by the climate change that lead to urban heat islands and pollution. This is mainly due to the high population density, the atmospheric emission from the private traffic use and industries [1]. The rate of air contamination in Barcelona exceeds the recommended levels by the World Health Organization. In addition, it is estimated that $66 \%$ of the population is exposed to excess Nitrogen Oxygen levels. All of this affect negatively the quality of life of the population living in Barcelona [1].

In fact, Eixample is one of the most exposed districts to the heat island effect in the city of Barcelona. Studies have found that there is a difference in temperature between this zone and rural areas of up to $7.5^{\circ} \mathrm{C}$, and the difference of temperature between Eixample and other districts of the metropolitan area can rise up to $3^{\circ} \mathrm{C}[9]$.

In addition to studying outdoor air quality in the Eixample, for this research it is important to know about indoor air quality, given the crucial role of intermediate living spaces. In fact, recent investigations agree that there could be many toxic compounds in indoor air, such as VOCs, $\mathrm{PAHs}, \mathrm{No}_{2}, \mathrm{CO}, \mathrm{CO}_{2}$ and heavy metals originated from human activities, cleaning products, furniture materials; outdoor air infiltration such as traffic pollution and industrial emissions also affect indoor air quality [10]. All of these factors represent a problem as it has been reported that most of the people spend $85 \%$ of their time in indoor spaces [10]. These effects can be countered with plants, which can improve indoor air quality (IAQ) by absorbing $\mathrm{CO}_{2}$ and releasing $\mathrm{O}_{2}$ through the photosynthesis, and increase air humidity by water vapor transpired from leaves through microscopic leaf pores [11].

Eixample is one of the densest and most extended districts in the city of Barcelona, which makes it the perfect area to start recovering the essence of a green city. This can be done not only through the urban intervention in public spaces, but also with small intervention at the domestic scale in the intermediate spaces of dwellings, which are the limit between the interior and the exterior, the public and the private, and could be enhanced through the implementation of greenery.

\section{PROMOTING A GREENER CITY}

During the last years, Barcelona City Council has developed plans, initiatives and subventions to mitigate the environmental problems in the city. Most of these plans promote the introduction of greenery and biodiversity in the metropolitan area. The principal goals of these measures are to reduce the negative effects of the urban heat islands and air pollution, increase the quality of life of Barcelona citizens, change the model of managing the urban nature, transform the urban space into a healthy and inclusive area and empower people for participation.

This investigation aims to find ways to collaborate with these actions promoted by Barcelona City Council integrating greenery in the existing building structure of the Eixample District. Some of these plans are the following:

\subsection{The Barcelona biodiversity plan 2020}

The plan seeks the introduction of nature in order to conserve and enhance the natural heritage of the city. The plan promotes a green infrastructure that shelters flora and fauna and it is part of the urban system conformed by buildings and urbanized areas. The intention of the Biodiversity Plan 2020 is to increase the biomass of the city; upgrade the existing greenery network; promote greenery in existing infrastructures such as roofs, facades, patios, and balconies, etc.; and boost the ecological agriculture in the city [12].

\subsection{The green infrastructure plan 2017}

The program aims at promoting urban green infrastructures in order to improve the quality of life of citizen and increase greenery in the city. As Barcelona has a dense layout it is difficult to establish new green spaces. The plan seeks to implement greenery in existing spaces such as green roofs, 
green walls and green balconies. The ultimate goal is to change the model of managing urban nature and the city itself by giving a significant role to greenery to play center in urban policies, urban planning, public health and sustainability [13].

\subsection{The tree master plan}

The plan goal is to improve the quality and quantity of trees in the city and their role as part of the city's green infrastructure. The plan establishes the managing of trees, since they are a universal natural resource, it also seeks for implementing native species, improve the biodiversity and creating quality public spaces [14].

\subsection{The climate plan 2030}

The plan seeks measures to face climate change, which generates $70 \%$ of the greenhouse gas emissions in the city and negatively impacts air quality, urban heat islands, energy flow, biodiversity, the city infrastructures and people's well-being. The plan pursues to reduce the levels of greenhouse gas emissions by increasing the urban greenery space and promote subsidies for collaborative citizen projects that aims at mitigating climate change. The goal of these measures is to increase the quality of life of Barcelona's inhabitants, recover the potential of available surfaces of roofs, party walls and facades to be productive spaces, transform public spaces into healthy, biodiverse and inclusive areas and empower people for collaboration and participation [1].

\subsection{Barcelona air quality improvement plan 2015-2018}

This plan presents measures to counter pollution in the air, moving forward to a more efficient society with lower emissions. The plan acts in mobility, energy, urban services, communication, and information. This Plan brings together other existing plans: Energy Climate Change and Air Quality Plan for Barcelona 2011-2020, the Urban Mobility Plan, the Energy Self-Sufficiency Plan and other additional measures relating to urban services, environmental education and communication [15].

The majority of these initiatives look forward to introducing greenery in the city at an urban scale, they treat the urban green infrastructure and its positive impact in the environment, improving the air quality and mitigating the urban heat island. The main objective is to give a significant role to greenery to play center in urban policies. Although there is an intention by the City Hall in involving society to collaborate in projects that mitigate the climate change and the city pollution, it has been hard to find an engagement from the citizens since the subventions promoted by the government contain many requirements, which sometimes are difficult to fulfill.

An opportunity seen by this research is that the company LTC works as a management bridge between the neighborhood community, as a private entity, and the subvention from the City Hall, as a public initiative. This makes it easier for the community to have access to subventions and grants.

For these reasons, the investigation looks for ways to implement greenery in the domestic scale through the building project of LCT. This may be done by taking advantage of the existing infrastructure of dwellings, and promoting the greening of their intermediate spaces, such as galleries, courtyards and surfaces as party walls and rooftops.

\section{INTERMEDIATE SPACES}

It is important to define what are intermediate spaces. They are thresholds, where the interactions between nature, the building element and people occur. They work as filters between indoor and outdoor areas. In the Mediterranean weather, which is characterized by hot summers and mild winters, the vegetation has been implemented in the interstitial space as a tool for climatic comfort, as protection against the solar radiation, the force of the winds, as well as to stabilize the temperature by shadow effect of trees and shrubs and by evapotranspiration of water [16].

In the Eixample District the traditional intermediate spaces presented in buildings are: balconies, galleries, terraces, courtyards. There are also surfaces related directly or indirectly with the interior spaces of the buildings such as the party walls and the rooftop.

In this investigation there is mainly treated greenery in intermediate spaces and surfaces that help to reconfigure the continuity of the Eixample block, that have lost its original geometry due to the changes in regulations explained before in chapter 2.

\section{GREENERY IN THE MEDITERRANEAN CONTEXT}

Greenery is defined as agricultural spaces or natural landscapes that offer ecological, environmental and social benefits, and increase the biodiversity of the city [17]. It is composed by vegetation, which is a living element that plays an important role in the beautification and protection of the urban environment in a Mediterranean context, such as Barcelona. It also has had a visual, aesthetic and climatic use within the buildings, and it is able to improve people wellbeing and quality of life.

Vegetation can have different effects in a domestic scale that impacts in the environment and the human quality of life.

In this research, it was determined the different effects of vegetation that altogether affect the comfort and well-being of the user in intermediate spaces, specifically in the industrialized housing projects of LCT in Eixample. These actions have to do with how green can act as a visual filter, as a dissipater of heat by shading effect, as a reliever of unpleasant noises, and as a cleaner of polluters in the air and a source of pleasant aromas.

\subsection{Vegetation as visual filter}

The physical characteristics of greenery, such as form, texture, size and color give visual value to vegetation. Its visual value represents the impact of the plant in its surroundings. Some characteristics of the plants are more dominant in a specific context than others and have higher visual value [18].

In intermediate spaces of the Mediterranean housing the visual impact of plants is able to hide unpleasant views by showing their organic shapes, different textures and bright colors.

The form is the 3-dimensional shape of the plants, which is usually used to classify greenery in: trees, shrubs, grasses, vines and palms. Groups of vegetation also form shapes that depending on the context could generate a very interesting visual effect, working as screens and buffers, ground covers or focal points [18]. 
On the other side, the perceived visual texture is about how the plant feel and looks. Texture can be seen in the leaves, flowers, branches and barks. Like form, a composition of different textures generate a high visual impact in the landscape [18].

Color is one of the most noticeable characteristics of vegetation, however, it can change depending on the season and time of the day. Color in vegetation is more saturated with summer sun and softer with winter light. High intensity colors have higher visual impact than weak intensity colors $[19,20]$.

\subsection{The solar heat dissipation and the shading effect by vegetation}

Plants are able to dissipate the solar heat on buildings through shading effect, reducing the long wave radiation exchange between the buildings thanks to the reduction of surface temperatures created by shading of plants [21]. Through the photosynthesis, the vegetation can absorb between $5-20 \%$ of solar incidence, reflect between $5-20 \%$, dispel by evapotranspiration between $20-40 \%$, emit $10-15 \%$ and transmit 5-30\% of energy [22].

In controlled spaces, the projected shadow of plants and the evapotranspiration phenomenon can generate differences in the temperature between $5-7^{\circ} \mathrm{C}$ and variations in the relative humidity of $10 \%$, in contrast with open spaces where wind changes the relative humidity very quickly [23].

\subsection{Vegetation and the urban noise}

Greenery affects noise attenuation through absorption by eliminating the noise, deviation by altering the direction of the noise, reflection by returning the noise to its origin, refraction by the circulation of noise around the vegetation and occultation by masking unpleasing noises with pleasant sounds [24].

However, it is difficult to determinate the attenuation of the noise by greenery because there are several variants that must be taken into account, such as the type and duration of the noise, the distance of the source of the noise from the receiver, the soil material, as well as the atmospheric conditions (humidity and temperature).

It is possible to observe that in the domestic scale, vegetation is able to concealed unpleasant noises with pleasant noises to the human ear, such as the sound of leaves and branches moving, and the sound of birds and other animals attracted by greenery.

\subsection{Vegetation as a cleaner of polluters and a source of aromas}

Greenery could act as a regulator in the exchange of $\mathrm{CO}_{2}$ and $\mathrm{O}_{2}$. Plants can reduce the $\mathrm{CO}_{2}$ in the atmosphere through carbon sequestration. Vegetation eliminates atmospheric $\mathrm{CO}_{2}$ and accumulate it in their biomass in form of carbon. The sequestration of carbon depends on the growth and mortality of the species.

Vegetation is also able to retain dust and residual particles from the air. Plants have a different absorption capacity that depends on the specie and the maturity of the plant, the availability of water and nutrients, and exposure to certain pollutants [17].

In addition to absorbing pollutants, plants emit odorous volatile substances. These aromatic substance levels tend to be higher when the flowers are ready for pollination and when potential pollinators are active. However, they not only come from the flowers but also form the leaves.

In intermediate spaces the position of vegetation and it scents play and important role, placing aromatic plants close to the limit between the interior and exterior areas could bring pleasant smells into the house, also positioning plants close to vertical wall allows the perfume to be better confined and captured.

\subsection{Effects of vegetation in human well-being}

Since the beginning of the civilization humankind has tried to remain close to nature. This is possible to see through the architecture history of the mystical Babylonian gardens, the Egyptian orchards, the pergolas and vines of the Roman Empire villas, the Renaissance gardens, as well as the patios and gardens of the Mediterranean, among others.

The need to be close to nature is related with a sense of wellbeing produced by nature elements in the human being. Recent studies show the positive effects of greenery in people. Roger Ulrich has conducted experiments showing different scenarios to people, he has showed natural landscapes in contrast with urban landscapes. As result, people have showed more interest by the natural landscapes and a more positive attitude [25].

As it was mentioned before, greenery improve people wellbeing and quality of life by regulating the microclimate, improving the aesthetic of the landscape, attenuating the noise by absorption or hiding unpleasing noises with nature pleasant noises, purifying the atmosphere by elimination of $\mathrm{CO}_{2}$, retaining dust and residual particles and emitting pleasant fragrances.

For these reasons, implementing greenery, such as small trees, shrubs and herbs in intermediate spaces of the existing dwellings of Barcelona could produce positive effects in the environment and people.

\section{GREEN PROJECTS IN THE EIXAMPLE BUILDINGS}

As it was explained in a previous chapter, the Eixample District is composed by a series of closed blocks. These blocks consist of a set of urban plots, where buildings are located, in the same perimeter delimited by the alignments of the road. The alignment of the road is the boundary between the road system and any other urban element.

These closed blocks present an interior courtyard, which is the space delimited between the rear alignments of the building defined by the different maximum buildable depths, and also between the limits of the block on the sides where no building is planned or only on the ground floor.

The urban regulations in the Eixample District were changing through the years from 1857 to 1986, as a result, different urbanism parameters were affected such as the occupancy of buildings, the heights, the number of floors, the buildable depth, the internal occupancy of the courtyard, the presence of attics and the ground floor occupancy area. As a consequence, the existing buildings in Eixample are characterized for presenting different buildable depths between 24-28 m, different facades lengths between 12-18 m wide and different building heights that can vary from 4 to 7 floors, resulting in a discontinuous skyline. 


\subsection{Analysis of the building housing typology}

The Eixample building have a rectangular plan organized with 4 or 2 apartments per floor, usually with a symmetrical facade and a central principal entrance, which is aligned with the vertical system of circulation in the center of the plan.

The building presents 2 facades: a principal facade to the street, characterized for presenting overhangs volumes such as balconies and terraces; and a rear facade to the interior block patio that is characterized for presenting galleries (Figure 2) [26].

Due to the large buildable depth, buildings count with interior patios of ventilation and illumination (Figure 2). These patios are usually aligned with a central axis, in front or behind the vertical circulation. There are some other patios located to the sides of the building, corresponding to the lateral party walls [27].

As buildings form part of the closed blocks, they lie next to each other and so the walls between urban plots are called party walls. They are visible from the inner patios. In addition, when buildings present different heights and buildable depths, party walls are exposed (Figure 2).

These buildings present a walkable rooftop, it consists in a flat and slightly sloping roof, without tiles, it was usually used for hanging the laundry, or as social venues. Nowadays these spaces are no longer used (Figure 2).

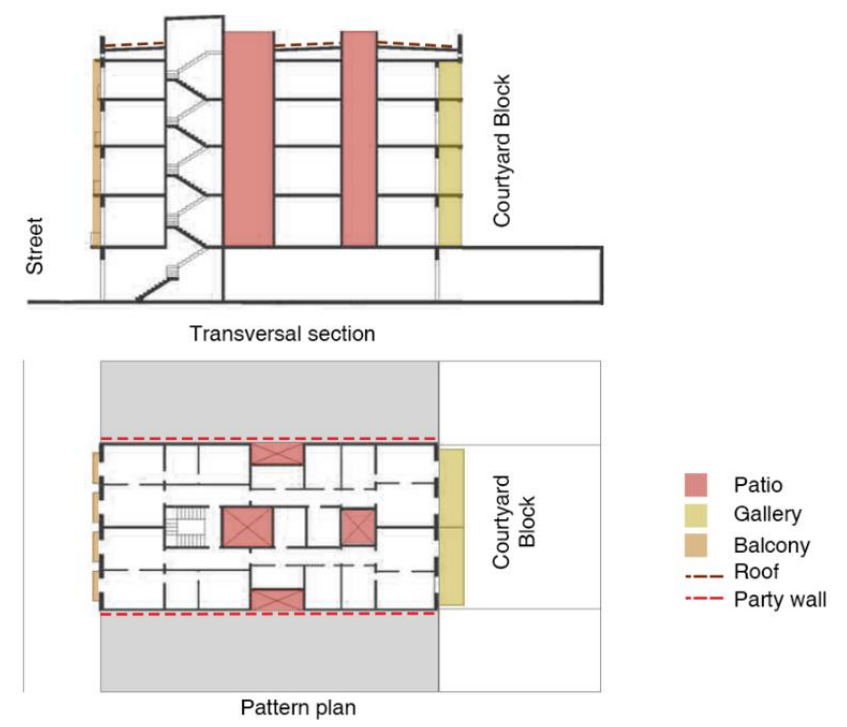

Figure 2. Typology of Housing in the Eixample District. Meignen, $\mathrm{F}$

Sometimes, when the maximum height is not completed, the building can grow vertically. However, any new additions must comply with the current city regulations, which allows the construction of penthouses as long as it respects the established height, and that such penthouses are 4 meters away from the facade line. As a result, a new terrace appears.

When a new intervention takes place, the building regulations demands to extend the inner patios to a measure of $3 \times 3 \mathrm{~m}$. As a consequence, in most of the cases, the patio facades of the new penthouse have to be moved backwards and an interior balcony appears.

LCT works fabricating industrialized penthouse adapting them to the city regulations and placing them on the rooftop of the existing buildings. The existing buildings are also entirely refurbished and intermediate spaces have a new connotation.
This is seen as an opportunity for this research to study these new intermediate spaces and, as mentioned before, implementing greenery to naturalize them and to the existing ones in the building.

In this way, the University Ramon Llul and the Department of Research and Development of the company LCT form a collaboration to develop an investigation about implementing greenery in the intermediate spaces of the intervened buildings.

\subsection{The potential of naturalized intermediate spaces in the Eixample building}

The Barcelona City Hall has found 30,7 ha of surfaces of party walls and roofs in existing buildings in the city with potential to be naturalized through greenery. If all these potential surfaces are naturalized, the amount of green area per person could increase a $15 \%$ [28], which will affect positively on the environment and the quality of life of the community. A $30 \%$ of the Eixample block buildings are able to grow not only vertically but also in depth, this is a potential area that can be used to add new green galleries to the city.

In order to understand the potential of implementing greenery in the intermediate spaces of the Eixample projects 10 interviews were made to architects and urban planners that have been working with the industrialized penthouses in the Eixample. They were asked the following questions: Do you think whether greenery could be integrable from the beginning of the project?; Which are the main obstacles found when implementing greenery in buildings?; Do you think there is a cultural problem in the city regarding the implementation of greenery in dwellings? If yes, which one?

The results were that $82 \%$ of interviewees considered that greenery is integrable from the beginning of the project because of the benefits to the environment, users and the improvement of the building aesthetic. The other $18 \%$ do not consider it integrable, since its success will depend on its adequate maintenance, and not necessarily the user who lives there will want to carry it out or deal with its costs (Table 1) [29].

Table 1. Question 1

\begin{tabular}{ccc}
\hline $\begin{array}{c}\text { Do you think whether greenery could be integrable } \\
\text { from the beginning of the project? }\end{array}$ \\
\hline \multicolumn{3}{c}{ Reason } \\
\hline \multirow{4}{*}{ Yes } & Improve the quality of life of users & $22 \%$ \\
& Many environmental benefits & $30 \%$ \\
& Improve the aesthetic of the building & $30 \%$ \\
\hline \multirow{2}{*}{ No } & Hight manteinance & $10 \%$ \\
& Cost of the project & $8 \%$ \\
\hline
\end{tabular}

For the second question most of the obstacles identified are economic, cultural and management problems. The majority of interviewees, specifically $60 \%$, agree that the economic problems are consequence of the costs of execution and maintenance of a green roof or a vertical garden, the other $20 \%$ of them argue about the lack of knowledge of available funding sources that promote the implementation of greenery in the city. The remaining $20 \%$ agrees that one of the main obstacles are managing problems related with a lack of experience in managing these spaces in a community basis. In this way, there are difficulties of agreement between the community of neighbors, the building owner and the project planners (Table 2). 
Table 2. Question 2

\begin{tabular}{cc}
\hline \multicolumn{2}{c}{$\begin{array}{c}\text { Which are the main obstacles found when } \\
\text { implementing greenery in buildings? }\end{array}$} \\
\hline Economic problems & $60 \%$ \\
Lack of knowledge of available funding sources & $20 \%$ \\
Maintenance & $20 \%$ \\
\hline
\end{tabular}

Regarding the third question $50 \%$ of interviewees believed that cultural problems are related with a lack of appreciation of the positive effects of greenery at different scales: the city, the building and the living space of the dwelling. For $20 \%$ of the planners think that the prejudices are related with damages that greenery can cause in the building structure, the high maintenance and the growth of insects in the building. Another $30 \%$ coincides that people in Barcelona is not used to meet in intermediate spaces, as result these have become forgotten areas (Table 3).

Table 3. Question 3

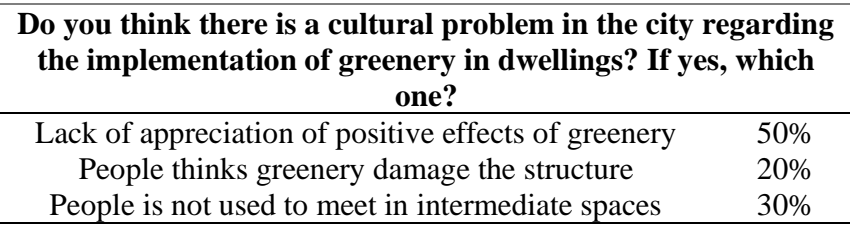

After evaluating the results, it is noted that there is a high amount of potential areas to be naturalized in the Eixample District and looking at the answers of the interviews, the study engages in proposing ways to intervene intermediate spaces and surfaces with greenery in a domestic scale, taking into consideration the difficulties found from the interviews and the benefits of greenery, as well as systematizing the solutions to achieve a better management and maintenance of these spaces.

\section{ANALYSIS OF THE CASE OF STUDY}

In order to study the different strategies to implement greenery in the domestic scale, first, 7 projects developed in Eixample by LCT were analyzed. They are buildings that had the opportunity to expand vertically and industrialized penthouses are placed in their roofs, adding a new store to the buildings. The analysis consists in studying the building context, the vertical and horizontal growth, the increase in the living space area, the structure system and the typology of intermediate spaces presented.

From these analysis, 3 buildings were selected. The projects were selected because they present different intermediate spaces with the highest potential to be intervened with greenery. The analysis consists in studying the architectural and structural characteristics of the intermediate spaces, its function, and how to implement greenery in these spaces at the project level.

The selected buildings are: Building Rambla Catalunya 82, Building Gran Via 553 and Building Roger de Lluria 41.

In these 3 buildings it was studied the different typologies of intermediate spaces and surfaces presented, creating an analysis sheet with drawings, where these spaces were classified. From then are developed: the gallery, which are located at the interior-exterior boundary of the building, looking to the street or to the block courtyard; the exposed party walls, the rooftops and the block courtyards.

The selection of these spaces was based in their high potential to be naturalized, and because all of them try to complete and reconfigure the silhouette of the Eixample block, enhance their image through the implementation of greenery, and contribute to increase the quality of life of their residents.

These intermediate spaces are analyzed in its architectonical and constructive features, and as well as the effect of greenery in their visuals, solar exposure and shadows, sounds and smells perceptions.

\subsection{The gallery}

The traditional Mediterranean gallery is an outgoing volume built on the rear facade of a house designed to extend the clothes, place the laundry room, or as social venues [30]. It is a long and narrow space throughout the height of the house, usually made with light construction materials, such as steel. Sometimes it presents sun protections elements of cloth or wood.

Many Eixample buildings present galleries at the rear facade that looks directly to the block courtyard typical from this district. Part of this block courtyards are usually occupied in the ground floor by workshops and local businesses, they have an approximately extension of $35 \times 35 \mathrm{~m}$, and compared to the street are very quiet spaces. These courtyards are usually disused spaces, that are currently being recovered with green areas or facilities to the community.

In the LCT Project Rambla de Catalunya 82, a penthouse and new gallery is added to the existing structure. The reasons why this gallery is placed in the building is because in first place, the original rear facade suffers multiple interventions through the years, as a result the facade has different constructive finishes and materials, some more deteriorated than others. In second place, the building has not reached the maximum buildable depth, so it has growth potential in plant.

The new gallery structure is hanging from the penthouse structure so it is does not rest in the ground, in this way the courtyard bellow does not lose any area with additional pillars.

The Gallery presents a double facade - the new facade and the existing facade-and this intermediate space acts principally as a filter for solar incidence and the climatic conditions of the Mediterranean climate, as well as an extension of the interior areas of the house.

The external facade of the gallery consists on sliding structures of aluminum slats (Figure 3 ).

In this typology of intermediate space, the relationship with nature is stablished with planters and pots, close to the railing boundary, as well as the implementation of aluminum cages with substrate and vegetation hanging from the wall or even conforming the railing structure.

The plants proposed are a mixture of evergreen and deciduous plants, in order to protect the intermediate space from the solar incidence in summer and get most of the solar incidence during winter. For instance, bright colors species such as the Hedera helix or pleasant-smelling plants like the Jasminum officinale, both are able to climb the facade structure. The users also plant species in flower planters, most of the cactuses and small shrubs.

Following the parameters of the positive effects of vegetation in the human well-being and quality of life it was analyzed the impact of greenery on the visuals, the sun exposure and shadows, the sounds, and smells. 


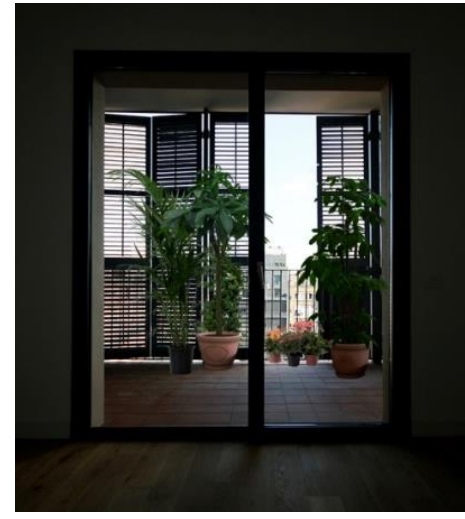

Figure 3. The gallery. Project: Rambla Catalunya 82. Image from LCT

\subsubsection{Visuals}

With the incorporation of vegetation at the gallery, an additional layer appears when looking to the courtyard and greenery become a filter of visuals to the exterior. It is still possible to see outside but now the vegetation accompanies the concrete of the neighboring buildings that conform the courtyard, it allows the eyes to rest and, at the same time, this layer of vegetation beautifies the perceived appearance of the context from the gallery. From the outside, the gallery is seen as a unique green facade that improves the aesthetic of the building, and it is a green focal point in their context.

\subsubsection{Sun exposure and shadows}

The gallery has a northeast orientation. As it was explained before, the gallery is made of sliding aluminum slabs that protect the space against the sun exposure. However, the presence of plants in this space increases the humidity and refreshes the ambience of the gallery.

\subsubsection{Sounds}

The gallery is located in a very quiet area, which is the traditional Eixample courtyard, this allows to listen to any single movement of the nature: the movement of the leaves and the branches with the air. As vegetation also increases the biodiversity, it is also possible to listen the sound of the birds singing during the day.

\subsubsection{Smells}

Smells in these galleries tends to be very neutral since they are not exposed to the street or kitchen areas, which are located close to the inner patios of the houses. For this reason, smells of vegetation are perceived by itself, it is possible to feel the sweet scents of flowers from the Jasminum officinale and intense aromas of herbs.

In this case study, the gallery is maintained by the users, it works as a community garden, there are several pots with vegetation that are individually managed. However, it is the sum of all this vegetation individually treated that generate positive impact in the environment and in the quality of life of its community.

This added green gallery provides the building with annex spaces of transition between the interior and the exterior, working as filter of visuals, as a source of climatic control with pleasant sounds and smells of nature. Although different interventions take place inside this gallery, which are given by each user, the gallery is seen from the outside as a unique green element.

\subsection{Party walls}

A party wall is a vertical partition that rises on the limit of two or more buildings. Although sometimes it could be visible from the public space, it is not considered a facade. Its continuity is interrupted, partially or totally, by courtyards of light or ventilation [30].

This extension of surface is usually forbidden, since they do not have a main role in the exterior appearance of the building, However, due to changes in urban regulations over the years, they have been totally or partially exposed, generating a discontinuity in the urban landscape, which can be seen from intermediate spaces such as courtyards and terraces.

In the intervened projects by LCT, it was possible to see that party walls are exposed when building presents different heights and depths, this is a consequence of changes in urban regulations. It is also possible to see the party walls of neighbor buildings from inner patios, from these spaces they are usually exposed.

For the reasons mentioned before, this research considers party walls as potential areas to be recovered with greenery. Vegetation can be a tool to integrate these urban discontinuities into the urban structure of the city, benefiting the environment and the quality of life of the community.

As a solution of these issues, in the project Gran Via 553 intervened by LCT, party walls are visible from the inner patios. In the LCT project when the penthouse is placed over the existing structure, inner patios of the new structure should be bigger than the exiting one, in this way the facade move backwards and a balcony in the inner courtyard appears. This balcony is a viewing platform to the patio and the neighbor exposed party wall.

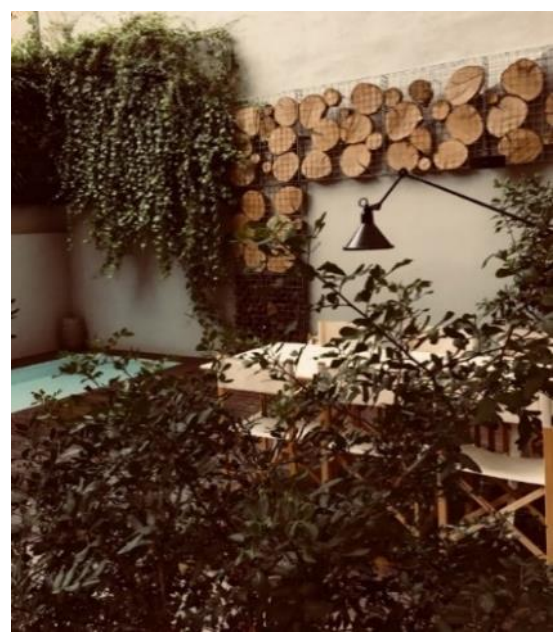

Figure 4. Green gabions at partition wall. Image from VERVEINE

In this project party walls can be treated as vertical garden with modular structures, such as gabions, hanging on the wall containing natural elements (vegetation, rocks and wood) (Figure 4), and with modular structures on the basement with climbing plants, and a mesh in front of the party wall, so it can be covered by vegetation and create a green screen visible from the inner balconies.

In this project is was possible to determine the following results when making the analysis about the impact of vegetation: 


\subsubsection{Visuals}

Vegetation in party walls creates a vertical garden, in this way, from the inner patio is possible to see the vibrant colors of greenery and visually perceive the course texture of the hanging plants as well as a pleasant composition of different forms. The gabion, a very orthogonal structure, mixes with the organic forms of greenery and at the same time works as canvas because it may contain different elements of nature, such as wood and stones, which add colors, shapes and textures to the composition.

\subsubsection{Sun exposure and shadows}

The solar incidence in the party wall of interior courtyards is degrading from the highest to the lowest floors. The lower part receives indirect sunlight and at the upper floor receive direct sunlight during the day. Vines more resistant to sun exposure are placed in the upper part of the wall, and vegetation that needs low sun exposure, as well as other natural elements, such as wood and stones contained in gabions, are placed in the lower part of the party wall.

\subsubsection{Sounds}

Sounds are neutral in these particular party walls; however, it is possible to note more sound coming from birds than before, the movement of the leaves and branches can also be heard.

\subsubsection{Smells}

In the particular place where the party walls are placed, which are the inner patios, there are many smells coming from the kitchen areas. However, odors of food are slightly hidden by the smells of nature, the earth and plants. In addition to release pleasant odors, due to its privileged position plants located in inner patios can filter and purify the air that enters directly into the home, reduce air pollution up to $30 \%$ and enhancing the oxygenation of air at the interior spaces of the building [31].

Unlike the gallery, this party wall needs a community agreement in order to be successfully maintained, it also needs an irrigation and water collection system. In its favor, the modular gabion element facilitates the gradually growth of the green wall. So, it can even be developed in stages if its needed.

This green vertical wall acts as a screen background from the interior spaces of the house, and an air purifier, cleaning the exterior air that goes directly into the house.

\subsection{Rooftops}

The roof is a virtually flat surface; it is the termination of a building or a construction [30].

In the LCT project when the penthouse is placed a new roof structure appears. This roof has the potential to be naturalized. In the project Roger de Lluria 41, when the industrialized building was placed over the existing one, a green roof is constructed in this area (Figure 5).

This green roof is made with a wooden platform, it counts with trees, like olive, shrubs masses placed in the boundary of the rooftop, small trees, shrubs and herbs, such as Fargensia nitida, Olea europaea, Citrus $\times$ sinensis, Petroselinum crispum and Mentha. The idea is that the rooftop acts as a social venue, linked to the work spaces that have been installed in the attic. It is a space where you can be close from the city, the nature and the sky.

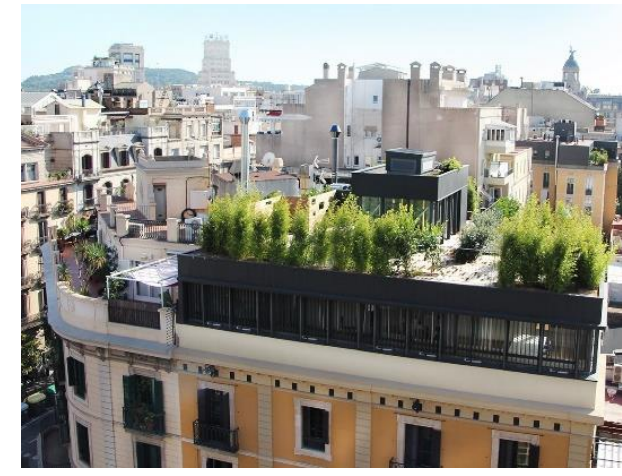

Figure 5. The rooftop. Project Roger de Lluria 41. Image from LCT

Once analyzed this space from the green effect parameters, the following results appears:

\subsubsection{Visuals}

The permeable mass of shrubs at the boundary of the roof allows to see through but the first vision are the intense colors of greenery, its perceived course texture, and only then it is possible to see the silhouette of the skyline; the green color soften the gaze toward the hard buildings at the other side of the street.

\subsubsection{Sun exposure and shadows}

Small trees like olives and medium shrubs can generate some shaded areas that give comfort to its users.

\subsubsection{Sounds}

This green room increases the biodiversity of the area as there a lot of birds that go to the roof, sounds of birds concealed street noises, also the rustling leaves and the breaking of the branches sounds induce calm feelings within a busy city.

\subsubsection{Smells}

In this area, greenery hides unpleasant smells from the polluted streets and replaces them for fresh scents of nature.

In this particular case, the green roof has a private maintenance, since it has the office LCT headquarters beneath. An automatic irrigation system is provided, but it needs constant pruning and maintenance.

The roof completes the silhouette of the Eixample block adding greenery to the skyline. The rooftop is a space where the urban structure of the city, the nature and the sky interconnect. At the visual level, this green space creates an overview of the tree tops from the street.

\subsection{Block courtyard}

It is an enclosed space inside or at one side of a building used to illuminate and aerate interior spaces.

In the Eixample building, the ground floor used to be destined to local businesses or workshops, with a higher buildable depth than the rest of the building areas. In this way the roof of the ground floor becomes a courtyard at the first floor.

This surface has also the potential to be naturalized being treated as a rooftop. In the project Rambla Catalunya 82, mentioned before, the structure of the new gallery was planned making an effort to avoid pillars in the ground, so the courtyard surface at the first floor did not lose any area. 
The block courtyard works as a social venue, there is some furniture made with smaller gabions filled with stones and wood.

This space is naturalized with domestic intervention with small trees, shrubs and herbs placed in pots. Some of these species are the Bougainvillea, the Ficus benjaminam and the Olea europaea. Here the user also has plants from his own urban garden, with species such as the Cucurbita pepo, the Raphanus sativus, the Daucus carota and the Solanum tuberosum.

The following results appears when analyzed this space from the green effect parameters:

\subsubsection{Visuals}

Since these courtyards are very extensible areas (10x6 m) plants act as focal points. Smalls trees and shrub masses organize the different living zones and are noticeable from inside the house, which filters the visual to the block courtyard and neighbor buildings.

\subsubsection{Sun exposure and shadows}

Small trees and shrubs generate shaded areas, these masses of plants also help to generate a microclimate by evapotranspiration, being able to decrease the temperature until $5^{\circ} \mathrm{C}[23]$.

\subsubsection{Sounds}

This area is really quiet in comparison with the street, is usually crowded by birds. Greenery in the courtyard helps to feel more closely the sounds of birds and nature, increasing the biodiversity in the city.

\subsubsection{Smells}

In this area smells are very neutral, so it is possible to perceive smells from nature, which can be boost by pots close to the facade of the building to help introduce these aromas into the house. It is possible to feel fragrant plants from medicinal plants such as: Anehtum graveolns, Ocimun basilicum and Chamaemelum nobile.

This space is privately managed by the inhabitant of the first floor. In this project the naturalization of the courtyard occurs at the domestic scale through pots that contain small trees and shrubs. Maintenance is considerably lower than green roof and vertical gardens. They are a green focal surface into the example blocks, which are visible from the rear facade of neighbor buildings.

\section{CONCLUSIONS}

After analyzing these spaces, it was possible to make the following conclusions:

All of them help to reconfigure and complete the silhouette of the Eixample block introducing greenery in the city.

For being an extension of the house, the gallery is closely related with the interior spaces so greenery feels almost inside the house, the concentration of nature aromas and sounds can easily enter inside, they have to travel a short route to access the home. A similar effect occurs in the interior block courtyard, being accessible from the living areas of the house, it is an open sky space surrounded by the neighbor buildings which could also bring nature aromas and sounds into the house, and because it is a huge extension of surface, vegetation scents can be perceived form the interior of the house.
On the other side, green party wall in inner patios are spaces visually connected with the house but that cannot be inhabited, they work as green background for the inner areas of the house and a purifier of the air that comes into the dwelling. Finally, the rooftop, it is not visually or physically connected with the house beneath. However, it becomes a garden, a space that stops feeling like a building and begins to be part of nature.

Regarding its maintenance and cost, the block courtyard and the gallery are spaces than can be easily treated from the domestic scale, their intervention can be made through small actions with vegetation, planters and pots and its maintenance depends on each user, so they required a low maintenance. The same cannot be said for the green party wall and green roofs, these need to be treated in an agreement with the community and in order to successfully manage and maintain these spaces, they require a higher maintenance, more expertise and a greater investment for its execution. However, in all the cases, the inhabitant gets used to the presence of green, recovering his links with nature in their everyday space.

Although the difficulties of agreement between the community of neighbors, costs and maintenance of vegetation represent a barrier for naturalizing the city, the public administration of Barcelona is trying to adapt to the European Union Guidelines about green infrastructures by developing initiatives, subventions and plans for diffusing the benefits of greenery.

The problem with these subventions and initiatives is that they are very difficult to implement in a city such as Barcelona. In order to execute a green project through a public subvention in a residential building, many actors (the neighbor's community, the building owners and the project planners) have to agree on its developing and achieve the requirements of the public administration to obtain the subsidy.

Considering these difficulties, a possible solution would be to encourage the implementation of greenery at different scales, going from the domestic scale of the dwellings to the urban scale of the city. As well as promoting the City Council subventions for implementing greenery an empowering the community to add green in the dwellings.

According to a study made by LCT, there are around 1,800 buildings in Eixample that can be vertically expanded [32], and they have potential intermediate spaces and surfaces that can be naturalized. In that case, this will result in approximately 65,52 ha. of new green areas in the district.

For these reasons, intermediate spaces: galleries; courtyards and surfaces like roofstops and party walls are potential areas to occupy through nature. Their naturalization could generate positive effects in the users improving their living experience and their health; in the buildings improving their energy performance; and in the environment, mitigating the climate change and the UHI, improving the interior and exterior air quality and increasing the biodiversity, as well as in the urban plot reconfiguring the silhouette of the Eixample block. In this way, the greenery added to the buildings combined with the green of the trees in the street reinforce and brings back the initial conception of the Cerdá plan.

It is important to highlight how a set of small interventions implemented together are able to generate significant impacts in the city. The naturalization of intermediate spaces in Barcelona could be also extrapolated to other cities in the Mediterranean context, this could also contribute to people's awareness about the benefits of greenery, the re-activation of spaces in disuse, and generate a culture that values the presence of nature in the city. 


\section{ACKNOWLEDGMENT}

This work is supported by the University Ramon Llull, and the Industrial Doctorate Plan of the Generalitat de Catalunya; It counts with the support of Veveine Company and its CEO Lina Seguró.

\section{REFERENCES}

[1] Barcelona City Council. (2018). Climate Plan. Area of Urban Ecology. Barcelona City Council, Barcelona. https://www.barcelona.cat/barcelona-pel-clima/es.

Accesed on Nov. 10, 2019

[2] Agència de Salut Pública de Barcelona. Informe de qualitat de l'aire de Barcelona. Agència de Salut Pública de Barcelona: Barcelona, 2018. https://www.aspb.cat/documents/qualitat-aire-2018/, Accessed on Nov. 17, 2019

[3] Lobaccaro, G., Tadi, M., Wyckmans, A., Palazzo, D. (2014). Green design strategies for urban heat island mitigation in a solar optimized access Eixample via IMM ${ }^{\circledR}$ methodology. WSB 2014 Conference Documentation.

http://www.wsb14barcelona.org/papers.html, accessed on Aug. 10, 2020.

[4] Chaparro, L., Terradas, J. (2009). Ecological Services of Urban Forest in Barcelona, Centre de Recerca Ecològica i Aplicacions Forestals. Universitat Autònoma de Barcelona.

https://www.itreetools.org/documents/302/Barcelona $\% 2$ 0 Ecosystem\%20Analysis.pdf, accessed on Oct. 18, 2019.

[5] Aibar, E., Bijker, W.E. (1997). Constructing a city: The Cerdà plan for the extension of Barcelona. Science, Technology, \& Human Values, 22(1): 3-30. https://doi.org/10.1177/016224399702200101

[6] Centro de Cultura Contemporánea de Barcelona Archivo Cerda. Ordenanza de Edificación 1986 http://www.anycerda.org/web/es/arxiucerda/fitxa/ordenanca-d-edificacio-de-1986/454, accessed on Nov. 1, 2019.

[7] Pasos, T. Thesis: El Patio del Ensanche un espacio público de proximidad. Universidad Politécnica de Barcelona, 2014. http://hdl.handle.net/10803/279315. Accessed on Nov. 18, 2019

[8] Vega, S. (2019). El plátano de sombra de Barcelona, ¿amigo o enemigo? https://www.elperiodico.com/es/extra/20160921/comoes-platano-sombra-barcelona-5387585, accessed on Nov. $1,2019$.

[9] Martín-Vide, J., Artola, V.M., Cordobilla, M.J., Moreno García, M.C. (2015). La isla de calor en el Área Metropolitana de Barcelona y la adaptación al cambio climático. Àrea Metropolitana de Barcelona, Barcelona. http://www3.amb.cat/repositori/CANVICLIMATIC/ME TROBS/METROBS UHI.pdf, accessed on Dec. 12, 2019.

[10] Paoli, L., Fačkovcová, Z., Guttová. A., Maccelli, C., Kresáňová, K., Loppi, S. (2019). Evernia goes to school: Bioaccumulation of heavy metals and photosynthetic performance in lichen transplants exposed indoors and outdoors in public and private environments. Plants, 8(5): 125. http://dx.doi.org/10.3390/plants8050125

[11] Brilli, F., Fares, S., Ghirardo, A., Visser, P., Calatayud,
V., Muñoz, A., Annesi-Maesano, I., Sebastiani, F., Alivernini, A., Varriale, V., Menghini, F. (2018). Plants for sustainable improvement of indoor air quality. Trends in Plant Science, 23(6): 507-512. https://doi.org/10.1016/j.tplants.2018.03.004

[12] Barcelona City Council. Barcelona green infrastructure and biodiversity plan 2020, Medi Ambient i Serveis Urbans - Hàbitat Urbà, Ajuntament de Barcelona, Barcelona. https://climateadapt.eea.europa.eu/metadata/case-studies/barcelonatrees-tempering-the-mediterranean-cityclimate/11302639.pdf, accessed on Dec. 10, 2019.

[13] Barcelona City Council. Government Measure: Stimulus Programme for city's urban green infrastructure. Barcelona City Council, Barcelona. https://ajuntament.barcelona.cat/ecologiaurbana/en/what -we-do-and-why/urban-greenery-and-

biodiversity/green-infrastructure-impetus-plan, accessed on Nov. 20, 2019.

[14] Barcelona City council. Trees for Life. Master Plan for Barcelona's trees 2017-2037. Barcelona City Council: Barcelona.

https://ajuntament.barcelona.cat/ecologiaurbana/en/what -we-do-and-why/urban-greenery-and-biodiversity/treemaster-plan, accessed on Aug. 10, 2020.

[15] Barcelona City Council. Plan to improve Air Quality in Barcelona (2015-2018). Barcelona City Council: Barcelona, 2015. https://ajuntament.barcelona.cat/ecologiaurbana/en/what -we-do-and-why/productive-and-resilient-city/bcn-airquality-plan, accessed on Dec. 10, 2010.

[16] Coch, H. (2003). La utilitat dels espais inútils: Una aportació a l'avaluació del confort ambiental a l'arquitectura dels espais intermedis. Universidad Politécnica de Barcelona. http://hdl.handle.net/2117/93423, accessed Nov. 14, 2019.

[17] Ochoa, J.M. (2009). Ciudad, vegetación e impacto climático: el confort en los espacios urbanos. Erasmus, Villa franca del Penedés. https://www.redalyc.org/pdf/948/94820714007.pdf, accessed Nov. 20, 2019.

[18] Hansen, G., Alvarez, E. (2010). Landscape design: Aesthetic characteristics of plants. ENH1172. Environmental Horticulture Department, UF/IFAS. https://edis.ifas.ufl.edu/ep433, accessed on Dec. 13, 2019.

[19] Kaufman, A., Lohr, V. (2004). Does plant color affect emotional and physiological responses to landscapes? Acta Horticulturae, 639. https://doi.org/10.17660/ActaHortic.2004.639.29

[20] Hansen, G., Alvarez, E., Hansen, G., Alvarez, E. (2010). Color in the landscape: Finding inspiration for a color theme. EDIS, 2010(4). https://edis.ifas.ufl.edu/ep425, accessed on Nov. 18, 2019.

[21] Chen, Y. (2006). The intervention of plants in the conflicts between buildings and climate- a case study in Singapore. National University of Singapore. Department of Building. http://scholarbank.nus.edu.sg/handle/10635/15511, accessed on Nov. 10, 2019.

[22] Basal, N., Hauser, G., Minke, G. (1994). Passive Design, a Handbook of Natural Climatic Control. Elsevier Science B. V., Amsterdam. 
[23] Hoerbert, M., Kirchgeorg, A. (1982). Climatic and air hygienic aspect in the planning of iner-city open spaces: Berliner grosser tiergarten. Energy and Buildings, 5(1): 11-22. https://doi.org/10.1016/0378-7788(82)90023-8

[24] Akbari, H. (1992). Cooling Our Communities, a Guidebook on Tree Planning and Light-Colored Surfacing. Superintended of Documents, Pittsburg. https://escholarship.org/uc/item/98z8p10x, accessed on Nov. 10, 2019.

[25] Ulrich, R. (1986). Human responses to vegetation and landscapes. Landscape and Urban Planning, 13: 24-26. http://dx.doi.org/10.1016/0169-2046(86)90005-8

[26] Solsona, X. (2015). La cara oculta de Barcelona: l'ambient a les galeries dels patis de l'Eixample Cerdà. Universidad Politécnica de Catalunya, Departamento de Construcciones Arquitectónicas, Barcelona. http://hdl.handle.net/2117/95780, accessed on Nov. 18, 2019.

[27] Hosta, A. (2016). El patio en la ciudad mediterránia. Su transformación en la vivienda colectiva en Barcelona. Universidad

Ramón

Llull. http://hdl.handle.net/10803/381255, accessed on Nov. 10 2019.

[28] Barcelona City Council. (2010). Cobertes i murs verds a Barcelona. Barcelona City Council, Barcelona. http://bcnecologia.net/sites/default/files/proyectos/doc cobertes_i_murs_verds_01m2010_0.pdf, accessed on Nov. 10, 2019.

[29] Meignen, F., Martinez, A., Marti, N. (2019). Renaturalization of the city of Barcelona. introducing greenery in Mediterranean buildings. WIT Transactions on Ecology and the Environment, 238: 301-309. https://doi.org/10.2495/SC190271

[30] Enciclopedia Catalana. Retrieved from: https://www.enciclopedia.cat/.

[31] Mike, G., Witter, G. (1985). Häuser Mit Grünem Pelz. Ein Handbuch zur Hausbegrünung. Edition Fricke, Koln.

[32] Artés, J., Wadel, G., Martí, N. (2016). Vertical extension and improving of existing buildings. The Open Construction Building Technology Journal, 11(Suppl. 1): 83-94. https://doi.org/10.2174/1874836801711010083 